\title{
Technical Solution for Complex Layer-by-Layer Tillage with Soil Formation Turnover
}

\author{
Sergey Belousov ${ }^{1,2, *}$ and Alexander Tsymbal ${ }^{3,4}$ \\ ${ }^{1}$ Kuban State Agrarian University named after I.T.Trubilin, Krasnodar, Russian Federation \\ ${ }^{2}$ Agrarian scientific center «Donskoy», department «North-Caucasus scientific-research institute of \\ agricultural mechanization and electrification, Zernograd, Russia \\ ${ }^{3}$ IME named after V.P.Goryachkin, Moscow, Russian Federation \\ ${ }^{4}$ RSAU-MAA named after K.A. Timiryazev, Moscow, Russian Federation
}

\begin{abstract}
The paper deals with the issues of mechanization of main tillage with the soil formation turnover, the problems of traction resistance and possible solutions. The article has an analytical character, the analysis of ways and means of a possible solution to the problem of reducing traction resistance is given based on the results of studying the works of leading scientists in this direction. A technical solution for improving the design of the dump plow body is proposed. The technical process of working with the use of proposed working bodies is also justified. In conclusion, the main results achieved so far are presented.
\end{abstract}

Mechanization of tillage in the cultivation of agricultural crops is a labor-intensive and important technological process, which consumes significant resources, both human and material. This process is particularly important when working in arid areas with low rainfall and high temperatures. Of the entire complex of tillage operations, dump plowing is the most labor-intensive and technologically complex. In different years, such scientists as V. P. Goryachkin, K. A. Polevitsky, G. N. Sineokov, and others worked on solving the problem of reducing the traction resistance of the dump plow. In the works of these scientists, it can be noted that if you first destroy the soil layer in front of the plowshare body, then the question of "blunt cutting" is solved, the turnover of the soil layer, from a physical point of view, becomes easier. We propose a technical solution that is aimed at partially solving this issue, namely: the installation of flat-cutting working bodies on each body of the plowshare from the side of the field sawn-off will ensure the stability of the course of the arable unit, reduce energy consumption and improve the quality of the technological process of deep soil loosening for row crops.

The steady motion of the dump plowshare can be considered as the motion of a solid body in a plane; this motion is run by the law of the motion of the trace of the center of gravity of the solid body or when considering the motion of a body in a continuous medium. This law can be considered from the point of view of the movement of the dump plowshare, based on the laws on the moments of the amount of movement. Thus, for a steady

\footnotetext{
*Corresponding author: sergey_belousov_87@mail.ru
} 
motion the main quantities control the movement of the plowshare (the mass of plowshares and the position of its center of gravity trace) (Prof. Goryachkin, Theory of the plowshare of the basis for the systematic calculation of plowshares Moscow -1927).

In our case, the proposed technological process of basic tillage with the soil formation turnover can provide a reduction in energy intensity of the process of dump tillage while simultaneously increasing the qualitative and quantitative parameters of the technological operation.

As a result of the patent analysis, a number of patents were selected that are close to our design. On their basis, a technical solution was proposed that corresponds to modern agrotechnological approaches, patents No. 2491807, 136674, 136275, 191882 were obtained for the main tillage in Figure 1.

The disadvantages of the considered designs and technical solutions are that the working bodies are installed so that their end faces towards the furrow cut, as well as the plowshare of the main plow.

Issues related to tillage, soil crushing during plowing and energy consumption, were considered by V. P. Goryachkin. The efforts of many researchers were aimed at finding the least energy-intensive and most effective way to destroy the surface layer of the soil, finding such means of influencing the internal connections in the soil, in which they were broken in the most effective way.

The effectiveness of the destruction of the soil by the working body will also depend on the process of deformation of the soil and the degree of stresses created in it, as well as the speed of propagation of the deformation. Studying the law of pressure distribution over the cross-section of the deformer, presented in the work, we easily came to the conclusion that to use a wedge-shaped working body is the most appropriate and effective way.

Observations of the division of a cracking soil layer in the form of a dry monolith with the introduction of a flat wedge into it showed that the net of cracks extends in the soil by up to $0.15 \mathrm{~m}$ and connects with natural cracks of the formation. The researchers explain this by the fact that the tensile forces produce a break in the brittle body with very small deformations, so even with a small thickness of the knife embedded in the soil, there are shear deformations of soil layers.

From the technological process point of view performed by the combined plowshare, the flat-cutting working body should optimally solve the following tasks: to destroy the formation and create cracks in it, thereby passing the smaller structural formation of soil blocks, to cut weeds and eliminate their clogging on the flat-cutting razor.

The technological result of the proposed technical solution is confirmed by the Russian Federation patents for the invention No. 2491807 "Plow"; the Russian Federation patents for utility models No. 136275 "Plow"; No. 136674 "Body of the dump plow", No. 191882 "Body of the plow" (Figure 1). Also, the result of this solution is an increase in the degree of crumbling of the soil, due to its differentiated, layer-by-layer depth, processing by the main additional flat-cutting working bodies, depending on the state of the soil and the predecessor, as well as a decrease in the traction resistance of the plow by reducing the pressure of the field board on the furrow wall [1].

The claimed technical result is due to the fact that the body of the dump plow contains not only serial working bodies, but also additional flat-cutting working bodies installed on the body from the side of the field cut at an angle of $15-45^{\circ}$ to the direction of movement of the plow, with the possibility of adjusting the height opposite to the angle of inclination of the plow and has a width equal to the width of the grip of one plow body [1].

The design solution (Figure 1 options 1, 2, 3,4) leads to an increase in the quantitative and qualitative performance of the dump plow, the installation of an additional flat-cutting working body contributes to the establishment of the process of dump plowing, both in the vertical and horizontal plane of the possible displacement of the arable unit [2]. 


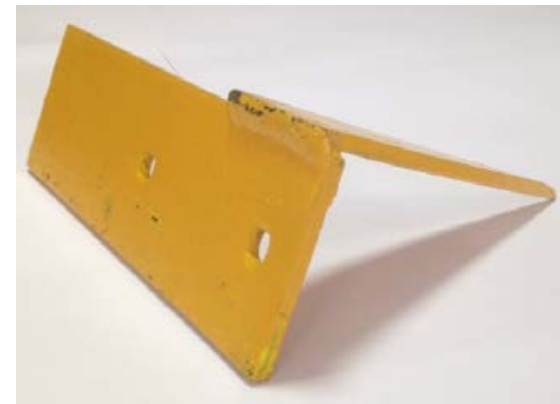

Model 1

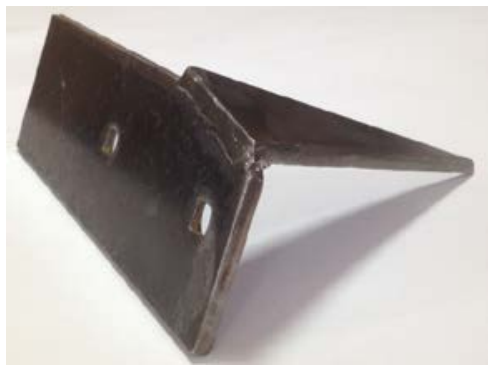

Model 3

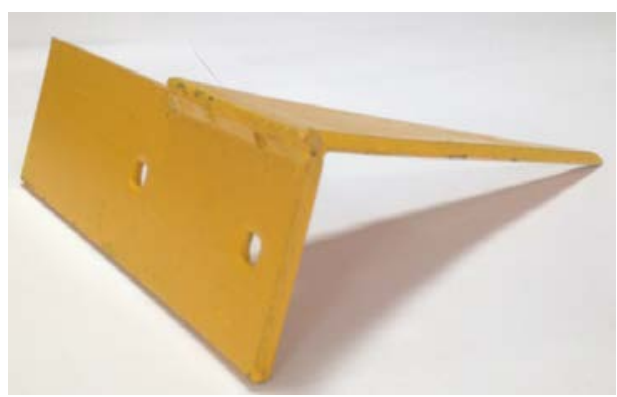

Model 2

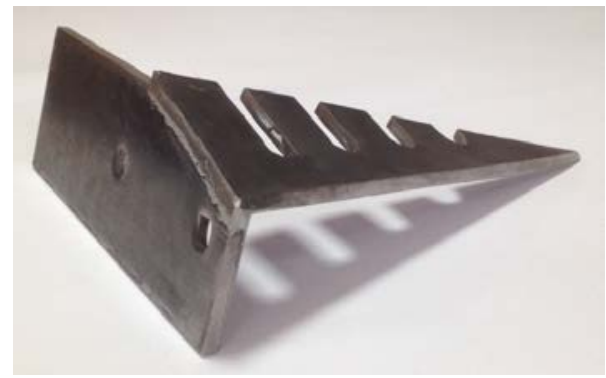

Model 4

Fig. 1. Types of flat-cutting working bodies tested during ongoing research according to patents № $2491807,136674,136275,191882$.

According to theoretical analyses, it is also known that in plows, the field board is pressed against the furrow wall with a force equal to the transverse component of the soil resistance [3]. In proportion to this force, there is a resistance to sliding friction.

In our case, the installation of an additional plane-cutting working body on the side of the field cutting will lead to a decrease in the resulting of transverse forces to the direction of movement, and to a decrease in forces of resistance to the friction of the field board against the soil of the furrow wall.

According to the stated technical solutions, working bodies were manufactured for laboratory and field studies (Table 1) and their tests were carried out on a serial dump plow $[3,4]$.

Table 1. Brief technological characteristics of the arable unit

\begin{tabular}{|l|c|}
\hline \multicolumn{1}{|c|}{ Parameter } & Value \\
\hline Working width of one plow body, $\mathrm{m}$ & 0,35 \\
\hline Working width of the entire unit, $\mathrm{m}$ & 1,4 \\
\hline Gripping width of the flat-cutting working body, $\mathrm{m}$ & 0,$2 ; 0,3$ \\
\hline Tractor for testing, $\mathrm{kW}$ & 67,01 \\
\hline Productivity per hour of shift time, ha/h & 1,1 \\
\hline
\end{tabular}


a

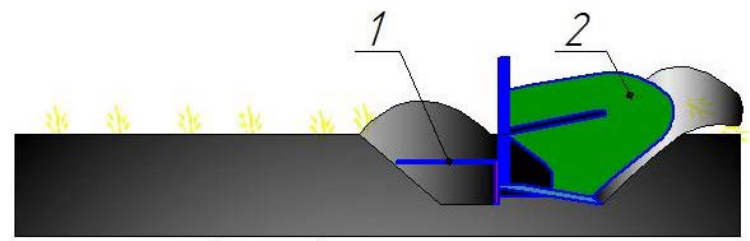

b

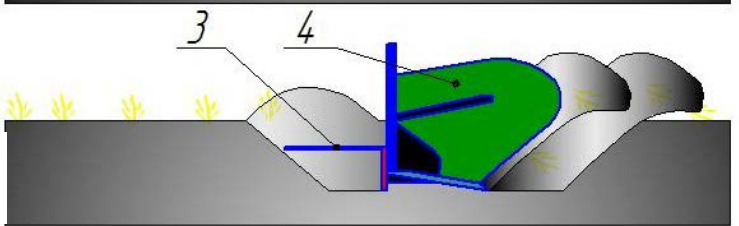

C

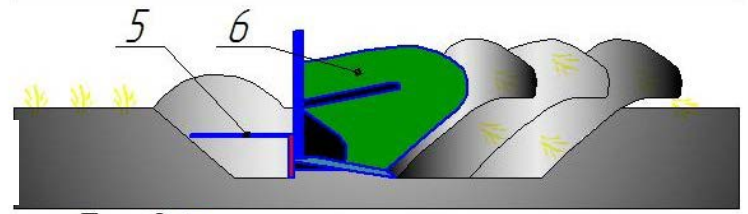

d

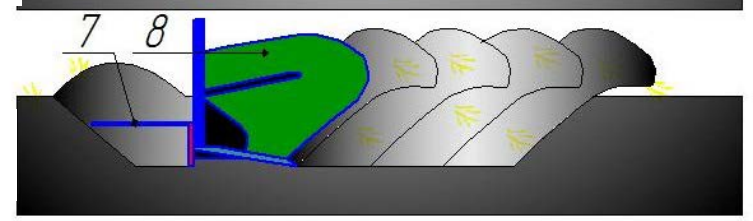

Fig. 2. Scheme of interaction of proposed working bodies with the soil:

1 - additional flat-cutting working body of the first plow body; 2 - first plow body; 3 -additional flatcutting working body of the second body of the plow; 4 - second plow body; 5 - additional flatcutting working body of the third body of the plow; 6 - third plow body; 7 -additional flat-cutting working body of the fourth plow body; 8 - fourth plow body 2):

According to the scheme of interaction of proposed working bodies with the soil (Figure

a) we observe the destruction of the furrow wall by the additional flat-cutting working body 1 of the first plow body 2, thus the undermining and preliminary destruction of the soil layer for processing by the second plow body 4 occur (Figure 2);

b) the destruction, in turn, of the furrow wall by an additional flat-cutting working body 3 for processing by the third body of the plow 6, on which an additional flat-cutting working body 5 is installed (Figure 2);

c) the destruction of the furrow wall for the processing of this soil layer by the fourth body of the plow 8 , on which an additional plane-cutting working body 7 is installed, which destroys the wall of the furrow for the processing of the soil layer by the first body of the plow 2 during the subsequent passage.

When using such working bodies on over-dried soils, the so-called Bauschinger effect can be observed, its essence is to reduce the resistance of the crystalline material to plastic deformation after a preliminary small plastic deformation of the opposite sign $[5,6,7]$.

Over-dried soil is a continuous homogeneous environment. If you act on such a soil with a flat-cutting working body, then the walls of the furrow are destroyed at a certain distance from the specified depth of processing and stress is created in the soil layer $[8,9$, 10]. The loading of soil particles by the working body reduces the break of physical bonds to small values, so when the plow body is repeatedly loaded in the opposite value and direction (compression), the material (soil) is deformed more easily than when the same direction is directly loaded. It follows that the destruction of the soil layer by an additional plane-cutting element leads to plastic deformation of the soil layer, and with repeated load- 
ing of the already destroyed soil layer, the process of reducing the traction resistance of the tillage unit can be observed $[9,11,12]$.

As a result of using this technique, we achieve the following agrotechnological solutions:

- the specific traction resistance on the arable unit is reduced;

- when preparing the soil for sowing, the number of additional passes of agricultural tillage machines in the field is reduced.

\section{References}

1. Belousov S.V. On the problem of interaction of the tillage working body with the soil Belousov S.V., Samurganov E.E. In proceedings: E3S Web of Conferences. "International Conference on Modern Trends in Manufacturing Technologies and Equipment, ICMTMTE 2020" 2020.P. 01062.

2. Belousov S.V.Theoretical justification of the type of a flat-cutting working body of a ploughshare Belousov S.V., Samurganov E.E., Rodionenko A.I.In proceedings: IOP Conference Series: Materials Science and Engineering. International Conference on Modern Trends in Manufacturing Technologies and Equipment 2019, ICMTME 2019.2020. P. 033100.

3. Belousov S.V.Mathematical processing of experimental data of the agricultural working body Belousov S.V., Belousova A.I. In proceedings: IOP Conference Series: Materials Science and Engineering. Cep. "International Conference on Modern Trends in Manufacturing Technologies and Equipment, ICMTMTE 2020 - Machine Science, Mechanization, Auotomatization and Robotics" 2020.P. 052059.

4. Belousov S.V.Design of the universal agricultural working body and study of its parameters Belousov S.V., Pomelyayko S.A., Novikov V.V. In proceedings: MATEC Web of Conferences. 2018 International Conference on Modern Trends in Manufacturing Technologies and Equipment, ICMTMTE 2018.2018. P. 05006.

5. Kambulov S.I., Rykov V.B., Trubilin E.I., Demina E.B., Kolesnik V.V. Influence of technology of soil processing on water supply of a processed soil layer. Multidisciplinary network electronic scientific journal of Kuban State Agrarian University. 2018. № 135. P. 50-57.

6. Rykov V.B., Kambulov S.I., Rykov V.B., Shaforostov V.D., Trubilin E.I. Layered combined soil cultivation: the basis of resource saving in field cultivation. Research Journal of Pharmaceutical, Biological and Chemical Sciences. 2018. Vol. 9. № 5.P. 1621-1630.

7. Rykov V.B., Kambulov S.I., Rykov V.B., Kolesnik V.V., Demina E.B., Ridniy S.D. Water supply of the processed soil layer at different tillage techniques. Innovations in agriculture. 2017. № 4 (25). P. 222-227.

8. Rykov V.B., Kambulov S.I., Kambulov I.A., Ridniy S.D., Kolesnik V.V., Demina E.B. Technological aspects of winter wheat cultivation using energy-saving technologies. Science in the central part of Russia. 2017. № 2 (26). P. 41-47.

9. Panov I. M. Perspective directions of development of tillage machines with active working bodies. M., CNIITEI of tractors and agricultural machines, 1971. $65 \mathrm{p}$.

10. Paraev A.G. The dependence of the traction resistance of a trailed tractor plow on the installation of its traction line in the horizontal plane // Mechanization and electrification of agriculture. - 1960. - Issue 55. - P. 307 - 317. - (Reports of TAA).

11. Matsepuro M.E. Problems of tillage equipment [Text] /under edition M.E. Matsepuro. - Vol. 8. - Minsk, 1962.-465 p.

12. Theory, construction and estimates of agricultural machines. Vol.1. M., Mashgiz, 1951. 574 p. Authors: N.P. Krutikov, I.I. Smirnov, K.F. Scherbakov, I.F. Popov. 